IZA DP No. 7865

Let's Be Selective about Migrant Self-Selection

Costanza Biavaschi

Benjamin Elsner

December 2013

Forschungsinstitut zur Zukunft der Arbeit Institute for the Study of Labor 


\title{
Let's Be Selective about Migrant Self-Selection
}

\author{
Costanza Biavaschi \\ $I Z A$ \\ Benjamin Elsner
}

IZA

\section{Discussion Paper No. 7865 \\ December 2013}

\author{
IZA \\ P.O. Box 7240 \\ 53072 Bonn \\ Germany \\ Phone: +49-228-3894-0 \\ Fax: +49-228-3894-180 \\ E-mail: iza@iza.org
}

Any opinions expressed here are those of the author(s) and not those of IZA. Research published in this series may include views on policy, but the institute itself takes no institutional policy positions. The IZA research network is committed to the IZA Guiding Principles of Research Integrity.

The Institute for the Study of Labor (IZA) in Bonn is a local and virtual international research center and a place of communication between science, politics and business. IZA is an independent nonprofit organization supported by Deutsche Post Foundation. The center is associated with the University of Bonn and offers a stimulating research environment through its international network, workshops and conferences, data service, project support, research visits and doctoral program. IZA engages in (i) original and internationally competitive research in all fields of labor economics, (ii) development of policy concepts, and (iii) dissemination of research results and concepts to the interested public.

IZA Discussion Papers often represent preliminary work and are circulated to encourage discussion. Citation of such a paper should account for its provisional character. A revised version may be available directly from the author. 


\section{ABSTRACT}

\section{Let's Be Selective about Migrant Self-Selection*}

Migrants are typically self-selected from the population of their home country. While a large literature has identified the causes of self-selection, we turn in this paper to the consequences. Using a combination of non-parametric econometrics and calibrated simulation, we quantify the impact of migrant self-selection on per-capita GDP in both sending and receiving countries. Two episodes of mass migration serve as examples: the migration from Norway to the US in the 1880s and the migration from Mexico to the US in the 2000s. We first estimate the degree of selection, and show that Norwegians were positively and Mexicans negatively selected. In a simulation exercise, we compare the economy under selective migration with a counterfactual in which the same number of migrants are neutrally selected. In both periods, we find virtually no aggregate effect in the US. Findings are different for the sending countries; migrant selection decreases Norwegian GDP by $0.3 \%$, and increases Mexican GDP by almost $1 \%$. While these effects may appear small, we demonstrate that the effect in Mexico is as large as the difference between no migration and the current level of migration.

JEL Classification: D33, F22, J61, O15

Keywords: international migration, selection, welfare

Corresponding author:

Benjamin Elsner

IZA

P.O. Box 7240

53072 Bonn

Germany

E-mail: elsner@iza.org

\footnotetext{
"We would like to thank the BiG MiG at IZA for the initial spark, and Samuel Bazzi, Anthony Edo, Jesús Fernández-Huertas Moraga, Luca Marchiori, as well as participants at ETSG 2013, CESifo, IOS Regensburg, University of Münster, and OECD Paris for helpful comments.
} 


\section{INTRODUCTION}

Migrant self-selection - the question who migrates and who doesn't - is one of the most fundamental issues in the economics of migration. A large literature has studied the if and why of self-selection: to what extent migrants and non-migrants are different, and what causes this difference. But despite the vast evidence of migrant self-selection from sending countries around the world, its consequences are far from clear. In this paper, we use two episodes of mass migration to study the aggregate impact of migrant self-selection on per-capita GDP in both the sending and the receiving countries.

We consider the emigration from Norway in the 1880s and the emigration from Mexico in the 2000s as examples for the two largest migration waves in the history of the US. Despite both episodes being 120 years apart, both sending countries are comparable in the scale of emigration and the level of development. Norway and Mexico had a GDP per capita of around one third of US GDP at the given period, and experienced an outflow of around $9 \%$ of the population. However, both differ fundamentally in the selection patterns of their emigrants. Norwegian emigrants were positively selected from the total population, while Mexican emigrants were negatively selected.

Our analysis combines non-parametric estimation with a calibrated simulation exercise. We first quantify the degree of selection by estimating the skill distributions for migrants and the total population. We use pre-migration wages as a proxy for skills, because wages include both observable and unobservable skills, and reflect a person's economic potential. For both countries we use panel data that contains information on pre-migration wages and subsequent migration decisions, allowing us to identify migrants in the wage distribution of the total population. For Norway, we obtain this data by matching historical census records. For Mexico, we use the ENET survey, a representative panel, which tracks migrants and stayers.

In a second step, we feed the estimated distributions into a calibrated general equilibrium model, and simulate the aggregate impact of self-selection. To understand the underlying thought experiment, consider the migration of around 10 million negatively selected Mexicans to the US. In our thought experiment, we repatriate all these 10 million migrants, draw 10 million new migrants from the total population, and send these 10 million new migrants back to the US. When comparing the US and Mexican economies before and after the experiment, the effect is purely driven by selection, as the number of migrants remains constant.

To quantify the aggregate impact of migrant self-selection, we use a general equilibrium model with heterogeneous workers, put forward by Yeaple (2005) and Iranzo \& Peri (2009). Within the model, a change in the selection pattern affects GDP per capita 
through two channels: nominal wages and prices. As self-selection changes the average skill-level of the workforce, it affects nominal wages through labor market competition. A more high-skilled workforce decreases the nominal wages for high-skilled workers relative to those of low-skilled workers. On the other hand, a more skilled workforce is also more productive, which decreases the aggregate price level. Overall, the price effect dominates the wage effect.

Our results demonstrate that migrant self-selection can — but not necessarily has to - have a significant impact on GDP. It only matters if both the size of the migration flow and the degree of self-selection are sufficiently large. In both periods we find virtually no effect on the US economy. The influx of 180,000 Norwegians in the 1880 s was simply too small to have any impact in the US. And even though the influx of 10 million Mexicans in the 2000s increased the US population by $4 \%$, the effect of selection on GDP only amounted to $+0.32 \%$. Because of the low degree of selection, the aggregate impact on Norwegian GDP is equally small; positive selection decreases Norwegian GDP in 1880 by $0.24 \%$. In Mexico, which had a large emigration wave with a significant negative selection, the effect is considerably larger. Because of negative selection, Mexican per-capita GDP is almost $1 \%$ higher than it would be if migrants had the same skills as all Mexicans. While the critical reader may consider this a small effect, we show that the selection effect is as big as the aggregate impact of migration per se - the difference between zero emigration and the currently observed level.

This paper offers a new perspective on the literature on the nature and causes of selfselection. In particular, it complements previous studies on self-selection from Norway (Abramitzky et al. 2012) and Mexico (Chiquiar \& Hanson, 2005, Fernández-Huertas Moraga, 2011, 2013, Ambrosini \& Peri, 2012; Kaestner \& Malamud, 2013). By quantifying the aggregate effect of the selection patterns found in these papers, it provides the reader with a complete picture of the causes and consequences of selective migration. Moreover, many studies on the causes of self-selection are motivated by the potential welfare impacts of self-selection. Our findings suggest that authors should be careful about making such claims, as selection only matters in one out of four cases in our study.

By showing that the composition of the migration flow can be as important as its size, this paper also advances the literature on the aggregate gains from migration. A series of papers quantifies the impact of migration on GDP using calibrated general equilibrium models. In large parts, these studies take the status quo as a benchmark, and estimate the welfare effect of a further reduction in the barriers to international migration (Hamilton \& Whalley, 1984, Felbermayr \& Kohler, 2007, Klein \& Ventura, 2007, 2009; Iranzo \& Peri, 2009; Docquier et al. 2012, Kennan, 2013), or take as counterfactual a world without migration (Di Giovanni et al. 2012). Depending on the modelling framework and the 
data, these papers predict significant overall gains from migration. Compared to these studies, we make two advances. While other studies mainly focus on changes in the size of the migration flows, we show that sizable welfare effects can even arise if we observed migration flows at the same level, but with a different skill composition. Also, due to data limitations, most of these studies only consider two groups of workers - high-skilled and low-skilled. Because we can rely on rich micro data, we are able to quantify the impact of migration along the entire skill distribution.

This paper can also inform the literature on the optimal design of migration policy (Djajić et al. 2012, Fernández-Huertas Moraga \& Rapoport, 2013). Through border enforcement and selective visa policies, governments in receiving countries can influence the selection of migrants in order to maximize gains from migration or voter shares Facchini $\&$ Testa, 2011). Our paper suggests that such policies can impose a substantial negative externality on the sending country, and may hit small sending countries particularly hard. Designing a compensation scheme would be difficult, especially if the losses in the sending countries are greater than the gains in the receiving countries.

\section{THE IF AND WHY OF SELF-SELECTION: WHAT WE KNOW SO FAR}

The literature on self-selection focuses on two questions: if and why - in what characteristics and to what extent migrants differ from non-migrants and why this difference exists. Both questions are important for our understanding of migration processes, and more broadly of demographic changes in sending and receiving countries. If migrants have better skills than non-migrants, migration changes the skill composition of the workforce in both countries; the sending country becomes on average less-skilled, while the effect on the skill composition in the receiving country is ambiguous depends on the average skills of natives.

Knowing the degree of self-selection is also important for understanding migrant outcomes. If we want to know whether migration makes people happier, healthier, or richer, then the degree of self-selection can inform us to what extent this effect is due to people moving from one country to another, and to what extent it is due to inherently different characteristics between migrants and stayers.

Further, self-selection can inform us about the determinants of migration flows. Do people migrate because of differences in incomes, better perspectives for their children, better amenities, or simply because they prefer living in another country? And do some people stay because migration is simply too costly, due to restrictive migration policies, 
financial constraints, or the absence of social networks? If we observe groups that migrate and groups that stay at home, it is possible to determine which factors are more important than others.

The theoretical underpinning for studying the causes of self-selection is the Roy-model (Roy, 1951), which has been formalized and applied to migration by Borjas (1987). In this model, the fundamental driver of migration is the relative returns to skill in sending and receiving countries. A wider income dispersion in the receiving country has the highest benefits for high-skilled migrants, and hence induces positive selection. The opposite is true if incomes are more dispersed in the sending country.

More recent studies have extended the basic model; Borjas \& Bratsberg (1996) allow for return migration, showing that the difference in the income dispersion between countries induces either the return of the best of the best, or the worst of the worst. While the basic model assumes that a potential migrant knows her income abroad, Bertoli (2010) proves that negative selection becomes more likely once migrants have imperfect information about incomes abroad.

Additional determinants identified in the literature are migration costs, networks, selective migration policies, and cultural proximity. Migration impose a larger hurdle for low-skilled emigrants and lead to a positive selection (Chiswick, 1999). This effect can be counteracted if migrants have access to migrant networks, which lower the migration costs and raise the expected income for low-skilled workers Carrington et al. 1996, Kanbur \& Rapoport, 2005, Pedersen et al. 2008, Bertoli \& Rapoport, 2013). Selective migration policies may influence selection directly by admitting only certain groups, or indirectly, by making migration more costly for some groups than for others. Finally, as shown by Belot \& Hatton (2012), closer cultural proximity between sending and receiving country makes it easier for less-skilled workers to migrate, leading to a more negative selection.

One of the most-studied cases is self-selection from Mexico. The first study of Mexico by Chiquiar \& Hanson (2005), drawing on data from the censuses of both countries, concludes that Mexicans are neutrally selected from the Mexican income distribution, and thus rejects the predictions of the Borjas (1987) model. But using censuses has the drawback that a researcher does not observe the same individual in both countries, which means that the selection measure is only based on observable skills. Recently available Mexican panel data, the ENET and the MxFLS, allows researchers to observe a person before and after migration, and to directly compute the skill distributions of migrants and the total population for both observable and unobservable skills. Several studies confirm the Borjas (1987) model, showing that Mexican emigrants are on average negatively selected (Ibarraran \& Lubotsky, 2007, Lacuesta, 2010, Fernández-Huertas Moraga, 2011, Ambrosini \& Peri, 2012; Kaestner \& Malamud, 2013). However, this average masks a 
significant rural-urban and male-female difference in selection patterns, which is due to differences in wealth constraints, access to migrant networks, and US border enforcement Orrenius \& Zavodny, 2005; McKenzie \& Rapoport, 2010, Fernández-Huertas Moraga, 2013).

Besides the US-Mexican case, the forces of the Roy model have been shown to drive migration selection from many other countries around the world. The evidence ranges from island states in the Pacific (Akee, 2007; McKenzie et al. 2010, middle-income countries in central Europe (de Coulon \& Piracha, 2005, Ambrosini et al. 2011) and South America (Bertoli et al. 2010), to the welfare states of Scandinavia (Rooth \& Saarela, 2007; Borjas et al. 2013). Furthermore, differences in the income distribution also drive the selection of migrants within a country. As shown for the US by Borjas et al. 【 (1992), people with the highest skills mismatch in a region are most likely to move. In Italy, where returns to skill in the rich North are lower than in the poor South, migrants moving North are negatively selected (Bartolucci et al. 2013). The differences in income distributions also explain the positive selection of rural-urban migrants in China (Xing, 2010), and of East-West migrants in Germany (Brücker \& Trübswetter, 2007).

Self-selection was also pervasive in historical migration episodes. Using matched census data from Norway and the US in the late 19th century, Abramitzky et al. (2012) find a small positive selection of Norwegian emigrants, although this finding is an average of a negative selection from urban and a positive selection from rural areas. Not only outflows from Europe were selective, similar patterns can be found for returnees from the US. Biavaschi (2012), based on micro data from the period 1908-1951, shows that US outmigrants were initially negatively selected, but the selection became more positive over time, as the US migration policy became more restrictive.

In sum, the existing literature provides a detailed picture on the causes - the if and why — of migrant self-selection, but remains silent on its consequences. In the following sections we will fill this gap and provide evidence for the aggregate effects of migrant self-selection during two major migration episodes.

\section{MigRANT SELF-SELECTION IN A MODEL WITH HETEROGENEOUS WORKERS}

\subsection{FINDING THE RIGHT COUNTERFACTUAL - INTUITION}

To determine the aggregate impact of migrant self-selection on per-capita income, we rely on a general equilibrium model with heterogenous workers, which will allow us to simu- 
late the effect of different self-selection scenarios on the sending and receiving countries. The simulation exercise is a thought experiment, in which we leave the level of migration constant, but change the skill composition of migrants. We exogenously replace $\mathrm{N}$ migrants with high skills with $\mathrm{N}$ migrants with the same skill level of the overall population, and compare the difference in aggregate economic outcomes. In this research design, the counterfactual is different compared to most studies on the aggregate impact of migration per se, in which the counterfactual is typically a world with a higher number of migrants.

Before going into the analytics of the model, we provide some basic intuition for the simulation exercise. Consider a world that consists of two countries - for simplicity, call them Mexico and the US. Both are endowed with high-skilled and low-skilled workers, as described by the Edgeworth box in Figure 1. Let A be the endowment of both countries before any migration happened. If workers migrate from Mexico to the US, the endowment point moves from A towards the upper right corner within the shaded area. If the endowment after migration lies on the dashed line from A to the upper right corner, migrants are neutrally selected. On this line the ratio between high- and low-skilled workers is the same for emigrants as it is for the entire Mexican population. Migrants are negatively selected if the new endowment lies North-West of the dashed line, and positively selected if it lies South-West of it. Points B, B', and B", which lie on a 45-line, represent migration flows with the same number of migrants, but different selection patterns.

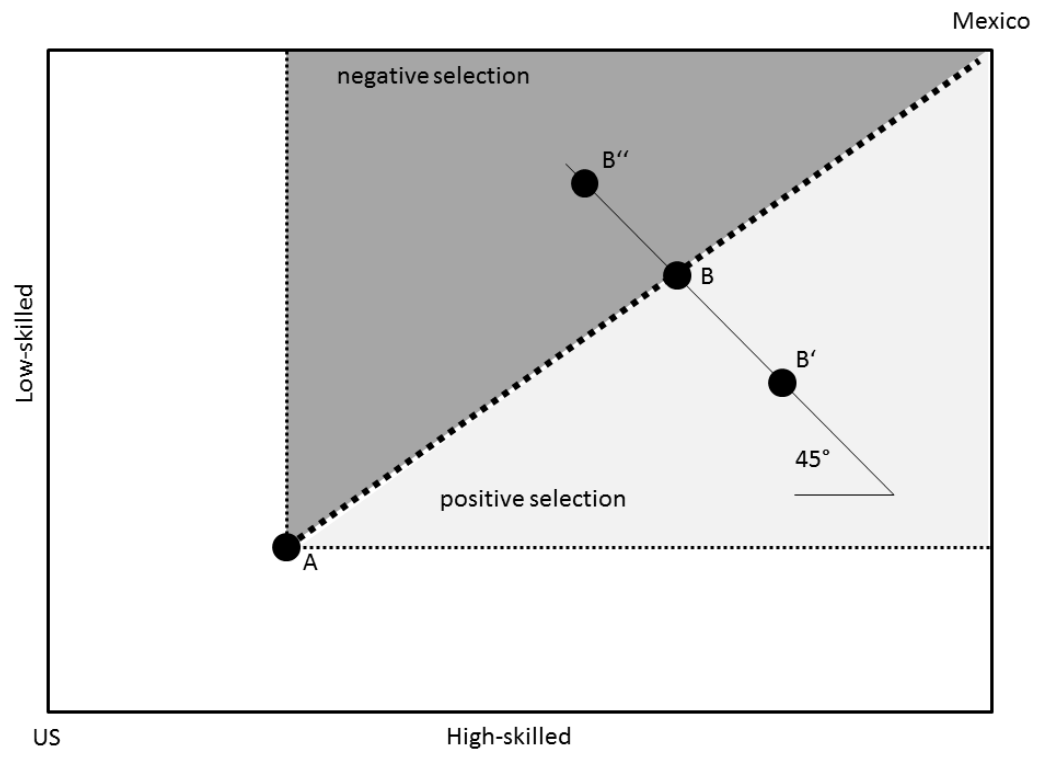

Figure 1: Migration from Mexico to the US. A: initial endowments without migration.

In the simulation exercise, we will compare the economy under the observed migration pattern, for example B', with an economy under neutral selection in point B. This strategy is conceptually different from the one applied in other studies, who either quantify the 
difference between autarky A and currently observed migration B' (Di Giovanni et al. 2012 ), or between the current migration B' and a scenario with more migration, in which case a new endowment point lies between B' and the upper right corner (e.g. Docquier et al. 2012, Kennan, 2013).

\subsection{BASIC MODEL}

Having laid out the basic intuition of our research design, we now describe the mechanics of the model. The model is based on heterogeneous workers, allowing us to study both aggregate and distributional effects of selective migration. It closely follows the work of Iranzo \& Peri (2009), who use a simplified version of a model developed by Yeaple (2005) to study the aggregate impacts of trade and labor market integration Europe. We will restrict the description of the model to its most important features, and refer the interested reader to Iranzo \& Peri (2009) for a full account.

Using the model, we want to study the impact of a change in the selection pattern of migrants on GDP per capita. As we do not model capital, GDP is measured as a weighted average of real wages.1 ${ }_{1}^{1}$ A change in migrant selection affects real wages through two channels: nominal wages and prices. Positive migrant selection makes the workforce in the receiving country more productive compared to neutral selection, leading to a decrease in aggregate prices. At the same time, positive selection increases competition among workers with higher skills, and decreases their nominal wages relative to those of less-skilled workers. As we will show, the productivity effect dominates the competition effect, hence positive selection will increase GDP per capita in the receiving country, while it has the opposite effect in the sending country.

We initially consider each country in autarky, assuming that trade flows do not respond to changes in the skill composition of migrants.2 A country's GDP is denoted by $\Lambda$. Each country is populated with a continuum of $M$ workers with skills that range from the least skilled worker at $Z=0$ to the most-skilled worker $Z=1$, with a cumulative density function $G(Z)$. in the sending countries, the initial population $M$ contains all stayers, while $M$ in the receiving countries includes both immigrants and natives. The economy consists of two sectors, $X$ and $Y$. Sector $Y$ can be understood as the more traditional sector, requiring mostly manual-intensive and routine tasks. Sector $X$ is the modern sector, involving complex tasks.

Sector $Y$ is perfectly competitive, and produces a homogeneous good with a constant returns to scale technology. Sector $X$ produces $N$ varieties of a differentiated good.

\footnotetext{
$1 \quad$ We do not model capital, as we are interested in the aggregate long-run effect. Even if capital was included in the model, the long-run outcome would be the same, as capital would fully adjust. 
Firms can freely enter sector $X$ after paying a fixed cost $F_{X}$ in the form of foregone output. The production technology in sector $X$ exhibits a higher degree of capital-skill complementarity $g_{X}$ than the technology in sector $Y, g_{Y}$, so that workers with higher skill levels $Z$ have a comparative advantage in sector $X$. Workers sort into the sector that pays them the highest wage. In equilibrium, workers above a threshold level $\bar{Z}$ will work in sector $X$, while workers with skills below $\bar{Z}$ will work in sector $Y . \bar{Z}$ is determined endogenously in equilibrium.

A worker in each sector produces $A_{Y}$ and $A_{X}$ units of goods $Y$ and $X$, respectively, with

$$
\begin{aligned}
& A_{Y}(Z)=\exp \left(g_{Y} Z\right) \\
& A_{X}(Z)=\exp \left(g_{X} Z\right) .
\end{aligned}
$$

Workers are paid their marginal product, such that unit costs are equalized across all skill levels within a sector. That is, the ratio of wage $W(Z)$ and productivity, $A_{Y}(Z)$ or $A_{X}(Z)$, is constant within each sector. The worker at the cutoff skill level $\bar{Z}$ is indifferent between working in both sectors, as she receives the same wage in both $W_{X}(\bar{Z})=W_{Y}(\bar{Z})$. In equilibrium, the wage schedule is

$$
W(Z)= \begin{cases}\Lambda \exp \left(g_{Y} Z\right) & 0 \leq Z \leq \bar{Z} \\ \Lambda C_{X} \exp \left(g_{X} Z\right) & \bar{Z} \leq Z \leq 1\end{cases}
$$

with $C_{X}=\exp \left(g_{Y} \bar{Z}\right) / \exp \left(g_{X} \bar{Z}\right)<C_{Y}$ being the unit costs in sector $X$. Good $Y$ is the numeraire, so that $C_{Y}=P_{Y}=1$.

Figure 2 illustrates the wage schedule in equilibrium. The wage schedule is linear in $Z$, with a kink at $\bar{Z}$ due to the higher returns to skill in sector $X$. The average nominal wage in equilibrium is

$$
\bar{W}=\Lambda\left(\int_{0}^{\bar{Z}} \exp \left(g_{Y} Z\right) d G(Z)+C_{X} \int_{\bar{Z}}^{1} \exp \left(g_{X} Z\right) d G(Z)\right) .
$$

To obtain real wages, $\bar{W}$ has to be divided by the aggregate price index $P=$ $\left[\beta^{\theta} P_{X}^{1-\theta}+(1-\beta)^{\theta}\right]^{\frac{1}{1-\theta}}$, with $P_{X}=\left[\int_{0}^{N} p(i)^{1-\sigma} d i\right]^{\frac{1}{1-\sigma}}$ being the price index for the differentiated good $X .^{3}$ Because we do not explicitly model capital, real GDP per capita can simply be calculated as average nominal wages $\bar{W}$ divided by aggregate prices $P$.

$3 \quad \beta$ is the share of good $X$ in the consumer's utility function, $\theta$ and $\sigma$ are the elasticities of substitution between goods $X$ and $Y$ and between $N$ varieties of $X$, respectively. 


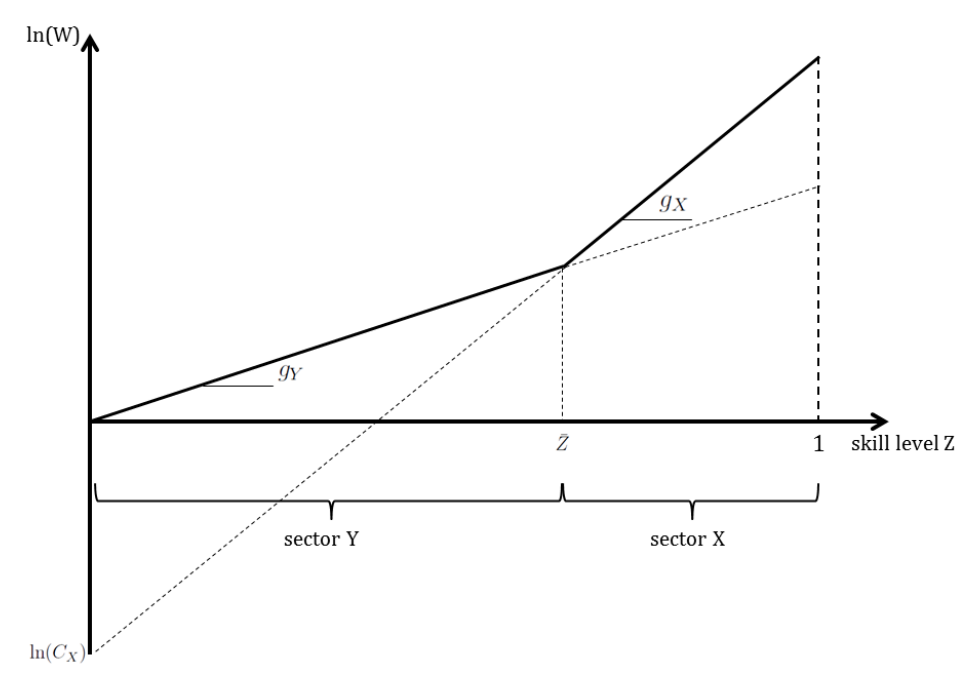

Figure 2: Equilibrium wage schedule.

Note: See Iranzo \& Peri (2009). The equilibrium wage schedule is the upper envelope of the wage schedule in sectors $Y$ and $X$. Workers self-select into the sector that pays a higher wage. The vertical axis denotes the log nominal wage in terms of the numeraire.

\subsection{INTRODUCING MIGRANT SELECTION INTO THE MODEL}

We now introduce migrant selection into the model and derive predictions for the effect of a change in migrant selection on income per capita. To measure the aggregate impact of migrant selection, we conduct the following thought experiment. We start with migration as observed, which means that out of the population $M_{S}$, a fraction $\alpha \in[0,1]$ with skill distribution $G_{M}(Z)$ have migrated from the sending to the receiving country. We then repatriate all $\alpha M_{S}$ migrants with skills $G_{M}(Z)$, and draw $\alpha M_{S}$ new migrants from the total population, which has a skill distribution $G_{S}(Z)$.

We speak of positive selection if migrants have on average a higher skill-level than all nationals of the sending country. Formally, this translates into first-order stochastic dominance of $G_{M}(Z) \leq G_{S}(Z)$. Migrants are

$$
\begin{array}{llll}
\text { positively selected } & \text { if } & G_{M}(Z) \leq G_{S}(Z) & \forall Z \\
\text { neutrally selected } & \text { if } & G_{M}(Z)=G_{S}(Z) & \forall Z \\
\text { negatively selected } & \text { if } & G_{M}(Z) \geq G_{S}(Z) & \forall Z .
\end{array}
$$

As an example, Figure 3 illustrates the effect of negative selection of migrants on the nominal wages in the sending country. The increase in the average skill level of the workforce increases the productivity in the $X$-sector, thereby reducing the unit costs of production in sector $X$. This leads to a downward-shift in nominal wages in the highskill sector $X$, and a shift in the cutoff between $Y$ and $X$ to the right. The relative 
wage decrease in sector $X$ can be interpreted as a competition effect on the labor market. More high-skilled workers increase competition and reduce nominal wages for higherskilled workers. At the same time, the sectoral re-allocation from the traditional to the modern sector makes the economy more competitive as a whole and reduces the aggregate price level.

Taken together, the effect on real wages depends on the sector. Real wages in sector $Y$ increase due to lower prices, while the effect in sector $X$ can be positive or negative, depending on whether the wage or the price effect dominates. In the receiving country, negative selection has the opposite effect. The total effect on real GDP per capita will be positive, yet the magnitude of the effect will depend on the structural parameters of the model.

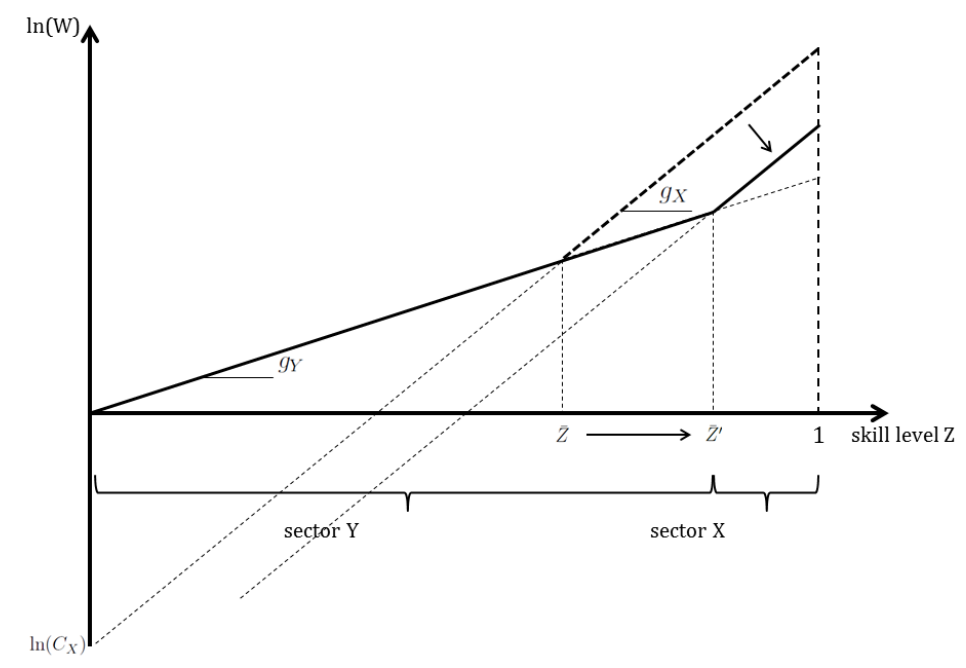

Figure 3: The impact of negative selection in the sending country.

Note: This figure illustrates the impact of a negative selection on the equilibrium wage schedule in the sending countries. If workers become more skilled on average, the cutoff skill level $\bar{Z}$ shifts to the right, leading to lower nominal wages in sector $X$.

\section{Estimating THE DEGREE OF SELF-SELECTION}

We now turn to the estimation of the skill distributions of migrants $\left(G_{M}(Z)\right)$ and of the total population $\left(G_{S}(Z)\right)$, which are at the basis of the model presented in the previous section.

We define a migrant to the US as an individual observed in Norway or Mexico at a given time, but who leaves for the US in the following period, when her household 
is surveyed again. A nonmigrant is defined as an individual who is observed in one of the sending countries at the time at a given time, and remains there in the following period. Following the most recent approach to measuring selection (Fernández-Huertas Moraga, 2011; Ambrosini \& Peri, 2012; Kaestner \& Malamud, 2013), we compute the degree of selection as the difference in pre-migration wages - or income, depending on data availability - between migrants and the full population. We rely on wages to measure skills for two key reasons. First, wages are a reduced form representation of a worker's productivity, which include both observable factors, such as education and experience, and unobservable factors, such as motivation and self-confidence. If migrants were positively selected from the sending population, we would expect their higher skill levels to translate into higher wages before migration. The opposite would be true in the presence of negative selection. The focus on wages allows us to be agnostic on whether selection is driven by observed or unobserved traits, obtaining instead a summary measure of the full economic potential of the workforce in both the sending and receiving countries. Second, the advantage of this procedure is that it avoids more complex exercises aiming at recovering counterfactual wage distributions for the two subgroups such as those in Chiquiar \& Hanson (2005) and Biavaschi (2012). Nonetheless, this procedure relies on the assumption that wages do not decline before migration. If migrants responded to future migration plans by changing current labor market effort, the procedure just discussed would overstate or understate the degree of migrants' selection depending on such response. Fernández-Huertas Moraga (2011) shows that such concerns are limited, at least in the case of Mexico, and we rely on this assumption in the rest of the paper.

We proceed now by briefly explaining our selection measure in each of the source countries and in the destination country. Full details on the data and variable constructions are presented in online Appendix A.

\subsection{Sending Countries}

Norway. We first study the flow of Norwegian born workers who migrated to the US in the second half of the nineteenth century. Such emigration flow is an illustrative example for the mass migration from Europe to the US in the second half of the 19th century, in particular from Scandinavia. Jensen (1931) reports that while up to the 1860s Scandinavian emigration rates were below the European average, the pattern reversed in later periods, with emigration substantially exceeding European rates. Between 1865 and 1880, the emigration rate from Scandinavia was more than 5 times as large as in the rest of Europe, with Norway driving this pattern. Besides being one of the most important sending countries during the age of mass migration, Norway offers the advantage of having 
almost complete digitalized censuses, allowing us to observe a large starting population. We use the 100\% Norwegian Census available in 1865, combined with the 1880 US Census, which is the only US Census that has been fully digitalized (Minnesota Population Center, 2008) $4^{4}$

We keep males 15-40 years old in 1865 5 and our goal is to attach to each individual an indicator of whether she will have migrated to the US by 1880 - i.e., whether she appears enumerated in the US census on that date. To this end we match the original Norwegian sample in 1865 to a US sample of Norwegian-born males 30-55 years old, following an iterative algorithm that has become standard in the economic history literature (Ferrie, 1996; Abramitzky et al. 2012) and that is explained in greater detail in online Appendix A. We define as migrants all individuals in the 1865 Norwegian census that we find in the 1880 census; everybody else is defined as a non-migrant.

Using pre-migration outcomes as a measure of selection complements the evidence given in Abramitzky et al. (2012), which was based on a cross-country comparison of postmigration income for migrant and non-migrant brothers. The advantage of our strategy is that we do not need to focus on households with multiple siblings and outcomes are measured in the sending country only, hence dissimilarities are not driven by international differences in the economic structure of sending and receiving countries ${ }^{6}$

Measuring selection in the early Censuses exhibits a further challenge: individual wages are not available. It is therefore necessary to rely only on differences in the occupational distribution of migrants and stayers and assign median income by occupation. Reliance on median income implies that selection can only be measured by variation across occupations and not within occupations. For instance, negative selection should be interpreted as migrants holding lower skilled occupations, although it might well be that within low-skilled occupations they are the highest ability workers. We use the crosswalk between HISCO occupations and median income provided by Abramitzky et al. (2012), who match income levels from Statistics Norway and other sources for 1900 and estimate incomes for farmers, fishermen and white collar workers. The counterfactual distributions are constructed focusing on occupations with an available estimate of average income (about $79.29 \%$ of the sample). Throughout we use the log of occupation-based

$4 \quad$ Over $95 \%$ of Norwegian emigration settled in the US, hence these sources should capture completely the migration flows and their selection pattern during this time period (Jensen, 1931).

5 We focus on such age group to reduce the risk of not finding individuals in 1880 due to mortality.

$6 \quad$ As an additional check, we run the same procedure linking the 1875 Norwegian census to the 1880 US Census. Such procedure allows a better comparison of our results with those in Abramitzky et al. 【(2012). Additionally, the shorter time span between the enumerations reduces the role that selective mortality might have in causing non-matches. Results are comparable to those in Abramitzky et al. प (2012): selection is positive also in this later cohort, although patterns differ between rural and urban areas. The overall conclusions of this paper do not change using this other sample. 
income in deviation from the average of the year as a measure of the skill distribution. We keep observations within two standard deviations from the mean, to assure enough dispersion in the distribution that will allow detecting differences between migrants and non-migrants.

For our simulation exercise, we divide the skill distribution in deciles and calculate the share of migrants and of the full population in each decile in 1865 . This procedure provides a non-parametric measure of selection that captures the impact of self-selection beyond changes in means and on all moments of the wages distribution.

To visualize the degree of selection, Figure 4 shows the estimates for $G_{M}(Z)$ and $G_{S}(Z)$, i.e. estimates of the cumulative skill distribution functions of the migrants and the total population. Migrants from Norway were on average positively selected. In fact, $G_{M}(Z)$ stochastically dominates $G_{S}(Z)$. The Kolmogorov-Smirnov test statistic for equality of both distributions gives a D-statistic of 0.0700 which yields to a rejection of the null of equality in the two distributions: migrants' wages are statistically different from those in the total population.

Figure 4: Cumulative Distribution Functions of Migrant and Full Population Skills, Norway 1865

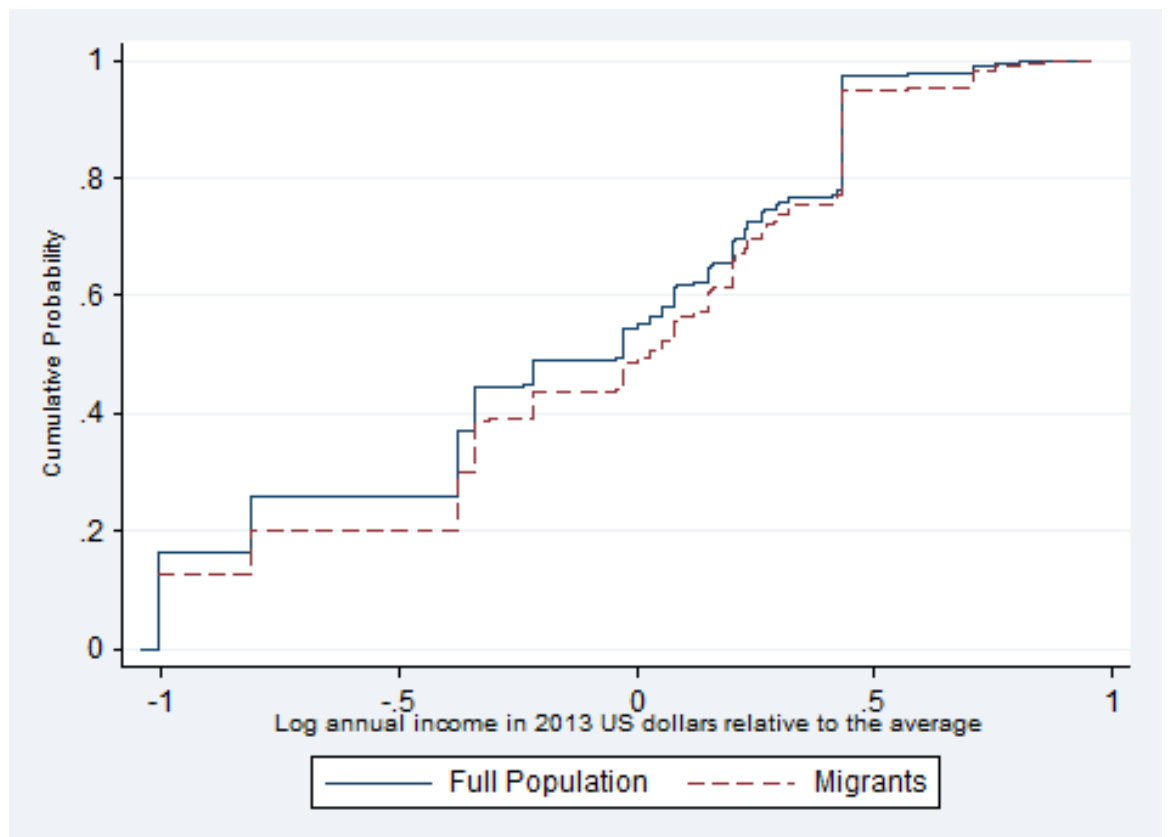

Source: 1865 Norwegian Census. Empirical distribution functions of the log of occupation-based median income relative to the annual average. See online Appendix A for variable construction.

Mexico Mexicans accounted for the majority of migrants in the most recent wave of mass migration to the US and their degree of selection has been intensively debated in 
the literature (Chiquiar \& Hanson, 2005, Ibarraran \& Lubotsky, 2007; Lacuesta, 2010, Fernández-Huertas Moraga, 2011; Ambrosini \& Peri, 2012, Kaestner \& Malamud, 2013).

To recover the distributions of interest we closely follow the steps in FernándezHuertas Moraga (2011). We use the Encuesta Nacional de Empleo Trimestral (ENET) from the second quarter of 2000 until the third quarter of 2004. The survey includes information on household members who left for the US and allows to compare migrants and non-migrants before migration. As with Norway, we define Mexican migrants as individuals who are present in Mexico at the time of the survey and are reported to have migrated to the US by the time of the follow-up survey (in this case, the following quarter). Non-migrants are individuals who are observed to be in Mexico throughout our sample period.

The final dataset comprises all the 2000-2004 data, with an identifier for all people who will migrate the quarter following the survey date. We restrict the sample to men between 25 to 65 years, with non-missing wage information, working at least 20 hours per week and less than 84 hours per week. As before, in constructing the wage distributions, we focus on individuals with wages within two standard deviation from the mean.

Figure 5: Cumulative Distribution Functions of Migrant and Full Population Skills, Mexico 2000-2004

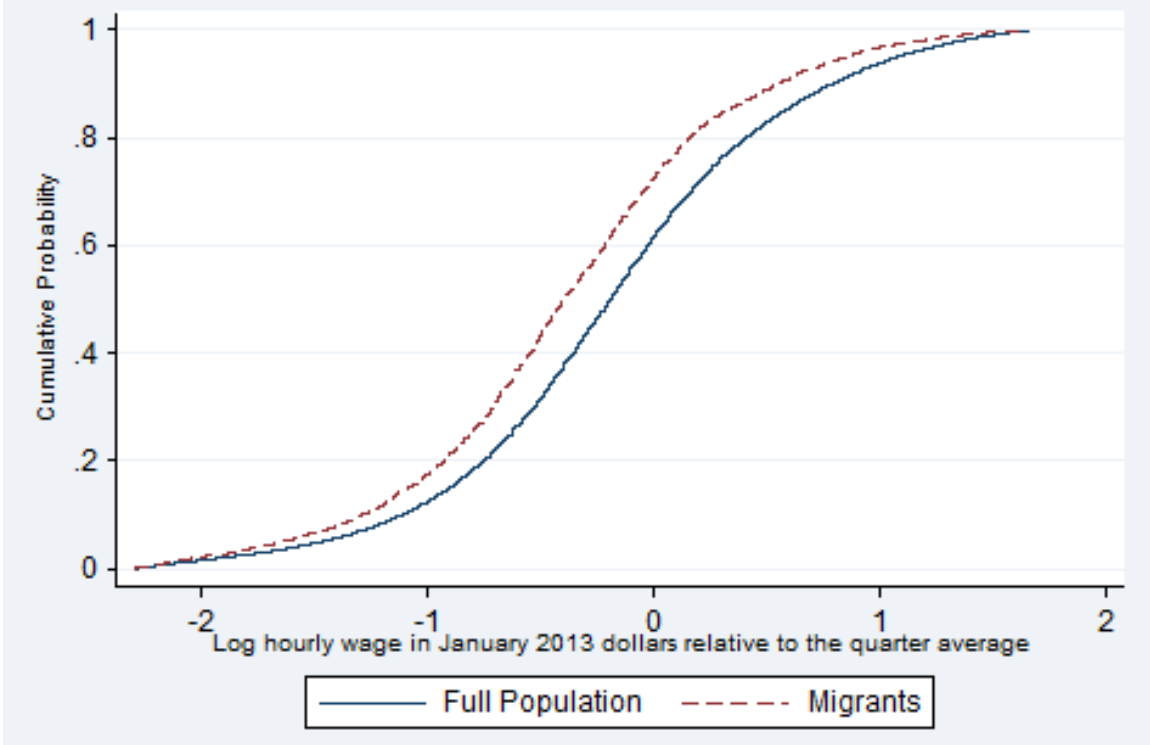

Source: ENET. Empirical distribution functions of the log-hourly wages relative to the quarter average. See online Appendix A for variable construction.

Following the same procedure applied for the Norwegian sample, we estimate the skill distribution for migrants and the full population based on pre-migration outcomes, 
i.e. pre-migration hourly wages in this case. Figure 5 shows $G_{M}(Z)$ and $G_{S}(Z)$. The migrant cumulative skill distribution lies above that of the full population, indicating that migrants are negatively selected. The Kolmogorov-Smirnov test statistic for equality in the migrant and counterfactual distribution gives a D-statistic of 0.0882 , yielding to reject at any conventional statistical level that migrants are drawn from the same distribution of the full population.

\subsection{Receiving Country}

To understand the aggregate effect that migrant selection has on the receiving country, migrants need to be compared to natives in the US, and we need to construct a counterfactual skill distribution that would occur if migrants were neutrally selected.

For the 1880 sample, we use the full US Census, restricting the sample to men, 15 to 40 years old. The income variable represents the median income by occupation in 1950, which allows us to rank individuals by nativity status using a consistent definition covering more than 200 occupations. We inflate the variable to 2013 US dollars. For the 2000s US sample, we use the 2000 Census. We focus on males, currently working at least 20 hours per week and less than 84 hours per week, 25 to 65 years old and construct hourly wages as the ratio of annual income and usual hours worked per year.

The cumulative distribution functions of Norwegians, Mexicans and natives are shown in Figure 6. Both Norwegian and Mexican migrants tend to have lower skills than the natives, although Norwegian migrants at the bottom of the skill distribution outperform natives. For the 1880 sample, the Kolmogorov-Smirnov D-statistic is 0.0695, for the 2000 sample the same statistics is 0.3593 . Both indicate that migrants and natives have different skills at any conventional statistical significance level.

To understand the consequences of migrant selection on the receiving country, our thought experiment requires to repatriate these selected migrants and instead draw a similar number of migrants from the full population of the sending country. If we had full transferability of skills and similar returns to skills across countries, the counterfactual distribution in the US would correspond to the distribution of the full population observed in the sending country, shown with the solid lines in Figure 4 and 5 . However, substantial downskilling is often present in the receiving country (Piracha \& Vadean, 2013 ) so that the support of the skill distribution in the sending and receiving regions might be rather different and the distribution in the sending country might not well represent the migrant skill distribution that would be observed in the receiving country if migrants were neutrally selected. In other words, being in the 9th decile in the Mexican skill distribution does not necessarily translate into being in the 9 th decile in the US 
Figure 6: Cumulative Distribution Functions of Migrant and Native Skills, US 1880 and 2000

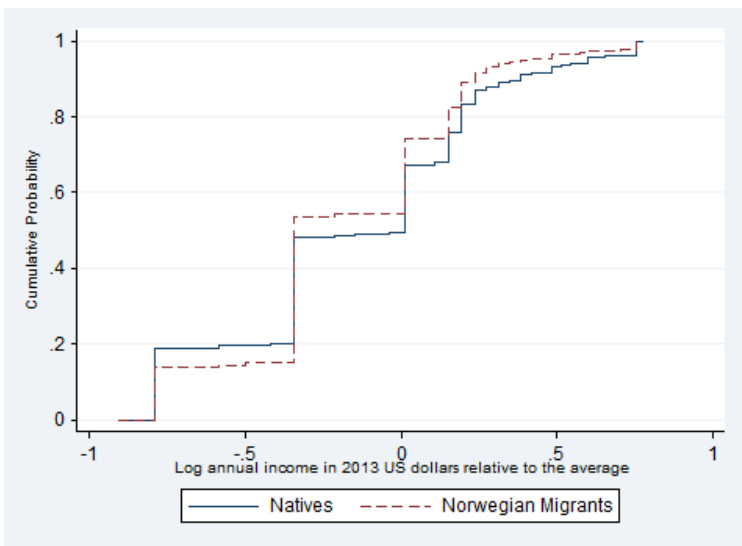

(a) US 1880

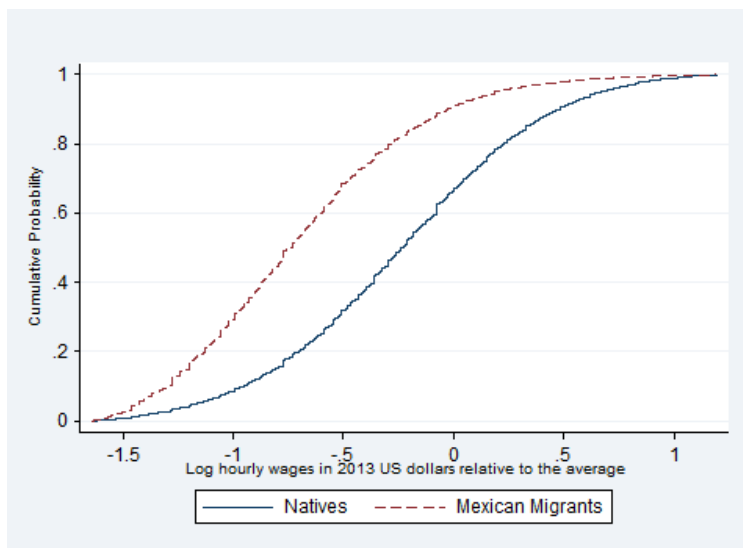

(b) US 2000

Source: 1880 and 2000 US Censuses.

In 1880: Empirical distribution functions of the log of occupation-based mean income relative to the annual average. In 2000: Empirical distribution functions of the log-hourly wages relative to the quarter average.

See online Appendix $\mathrm{A}$ for variable construction.

skill distribution. Moreover, the same skills may be rewarded differently in the US than in Mexico, and migrants and natives with the same observable characteristics are not necessarily perfect substitutes in the US labor market (Borjas et al. 2008, Ottaviano \& Peri, 2012).

To make the skills of neutrally selected immigrants comparable with those of US natives, we discount them using the relative difference between the observed skill distribution of immigrants in the US and in the sending country as weights. To obtain the counterfactual skill distribution of immigrants in the US, we multiply the share of the population in the sending country in the $i$-th decile, $d_{i, \text { send }}^{\text {Pop }}$, with a weighting factor consisting of the share of migrants in decile $i$ in the receiving country wages distribution, $d_{i, \text { receive }}^{\mathrm{Mig}}$, over the share of migrants in decile $i$ in sending country wages distribution,

$$
d_{i, \text { receive }}^{\text {Count }}=d_{i, \text { send }}^{\text {Pop }} * \frac{d_{i, \text { receive }}^{\text {Mig }}}{d_{i, \text { send }}^{\text {Mig }}} .
$$

$d_{i, \text { receive }}^{\text {Count }}$ is then divided by the sum of all weights $\sum_{i} d_{i, \text { receive }}^{\text {Mig }} / d_{i, \text { send }}^{M i g}$ so that the deciles of the counterfactual distribution sum to one.

As an example, Figure 8 shows both the unweighted and weighted counterfactual distributions for Norwegian and Mexican-born workers in the US in 1880 and 2000. Imposing neutral selection brings to the US more negatively selected Norwegian migrants and more positively selected Mexican migrants compared to the actual skill distribution observed in the two time periods. However, reweighing smoothes such differences, especially in the 
Figure 8: Actual and Counterfactual Cumulative Distribution Functions of Native, Norwegian and Mexican Migrant Skills, US 1880 and 2000.

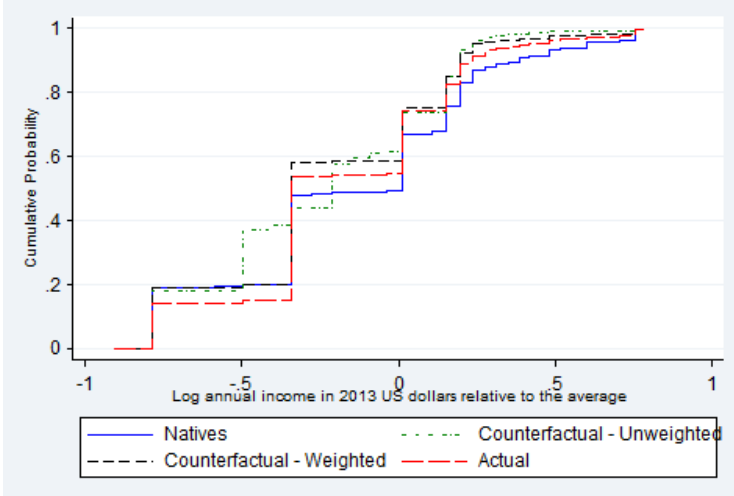

(a) US 1880

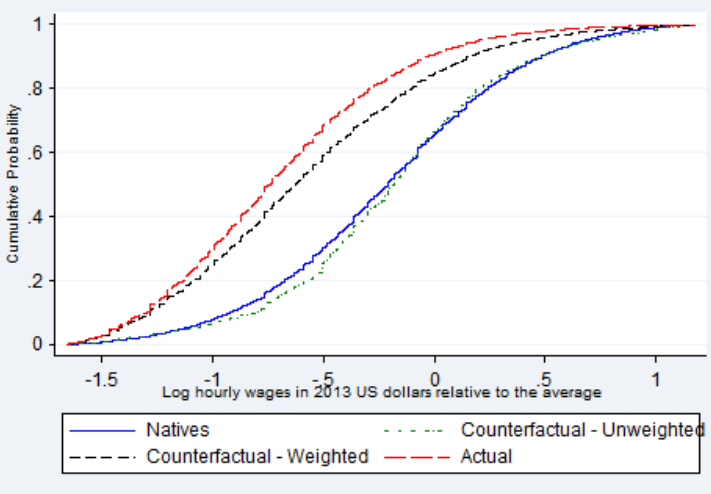

(b) US 2000

Source: 1880 and 2000 US Censuses.

In 1880: Empirical distribution functions of the log of occupation-based mean income relative to the annual average. In 2000: Empirical distribution functions of the log-hourly wages relative to the quarter average.

See online Appendix $\mathrm{A}$ for variable construction.

Mexican sample where selection was more apparent in the sending country.

\section{THE AGGREGATE IMPACT OF SELF-SELECTION}

We now turn to the aggregate effects of selective migration. In a thought experiment, we compare aggregate outcomes under the observed migration patterns with a scenario in which migration occurs at the same level, but migrants have the same skills as all nationals of the sending country. The difference between baseline and counterfactual gives us the aggregate effect of migrant self-selection. As a first step, we calibrate the model outlined in Section 3 on the economies of Norway and the US in 1880, and Mexico and the US in the early 2000s. We then feed in the estimated skill distributions of migrants and the total population from Section 4 , and calculate the difference in aggregate outcomes under different migration regimes.

\subsection{CAlibration}

To obtain an accurate estimate of the aggregate impact of migrant selection, we calibrate the model such that it replicates the basic features of the economies of the sending and receiving countries at baseline. We take most parameters from the literature or calculate them from available data sources. For parameters that cannot be calculated, we pick values such that key moments generated by the model match the real world data. Table 1 summarizes the calibration. 
Table 1: Parameters for calibration

\begin{tabular}{lccccc}
\hline & Parameter & Norway 1865 & USA 1880 & Mexico 2000s & USA 2000s \\
\hline$\quad$ External parameters & & & & & \\
Returns to skill, sector $Y$ & $g_{Y}$ & 1 & 1 & 1 & 1 \\
Returns to skill, sector $X$ & $g_{X}$ & 0.94 & 1.65 & 2.02 & 1.64 \\
Population: stayers, natives & & 1,702 & 43,391 & 101,826 & 244,000 \\
Emigrants to US & & 183 & & 10,017 & \\
Immigrant stock, all countries & $\Lambda$ & & 1,414 & & 26,588 \\
TFP & & 0.3195 & 1 & 0.286 & 1 \\
\hline Internal parameters & $F_{X}$ & & & & 15 \\
Fixed cost in sector $X$ & $\beta$ & 0.191 & 21,875 & 38,200 & 0.52 \\
Preference share of $X$ & $\theta$ & 1.50 & 0.42 & 0.51 & 1.54 \\
Elasticity of substitution $X$ and $Y$ & $\sigma$ & 4.05 & 4.19 & 4.12 & 3.82 \\
Elasticity of substitution, varieties of $X$ & $\sigma$ & & & & \\
\hline
\end{tabular}

Note: Population and migrant numbers in 1000s.

The population is measured as the number of non-migrants in the sending countries and natives in the receiving countries. The migrant numbers are taken from the censuses of the receiving countries. The sources are: for the number of natives and immigrants the US census in 1880 and the 2000 US census; for non-migrants in Norway the Norwegian census in 1865, and for non-migrants in Mexico the OECD population statistics in 2002. TFP in the US is normalized to one. The TFP level for Norway is based on Williamson (1995). For the difference in TFP between Mexico and the US in the 2000s, we use the differences in labor productivity levels provided by the OECD. For $g_{X}$ we use the estimates from Caselli \& Coleman (2006) for Mexico and the US in the 2000s, while for Norway and the US in 1880 we follow Goldin \& Katz (2007) and take the income ratio between the 90 th and the 10th percentile of the skill distribution in sector $X$ and $Y$. We normalize the returns to skill in sector $\mathrm{Y}, g_{Y}$ to 1.7

The sectoral classification is based on the ISCO (HISCO in our historical samples, van Leeuwen et al. 2002) standardized occupational classifications, and classify occupations into skilled and unskilled. 8 We choose the fixed costs $F_{X}$, together with the preference parameters $\beta, \theta$ and $\sigma$, such that the model outcome matches the observed sectoral distribution, as well as quintiles of the observed nominal wage distribution. Online Appendix B provides details on the numerical procedure used to compute these internal parameters.

$7 \quad$ Note that in Norway the returns to skill in sector $X$ are larger than in sector $Y$. This surprising finding is driven by the relatively large incomes for farmers in Norway in 1880, who had higher average incomes than workers in complex occupations in urban areas.

8 Skilled occupations are: Legislators, senior officials and managers, Professionals, Technicians and associate professionals, Clerks, Service workers and shop and market sales workers. Unskilled occupations are: Skilled agricultural and fishery workers, Craft and related trades workers, Plant and machine operators and assemblers, Elementary occupations . 


\subsection{Simulation RESUlts}

Based on the calibration shown in Table 1, we now simulate the changes in the skill distribution of migrants, and calculate its effects on sending and receiving countries. Before we turn to the results, let us first recall the predictions from the theoretical model. For the receiving countries, a more positive selection of migrants leads to a more skilled workforce, and shifts the cutoff skill-level between both sectors to the right. This shift affects real wages through two channels, nominal wages and prices. A more skilled workforce increases competition in the labor market for workers with higher skills, and decreases their nominal wages relative to those of lower-skilled workers. At the same time, a more-skilled workforce produces more output per capita, which decreases aggregate prices. Because the price effect is larger than the competition effect, the total effect on real wages is positive. For sending countries, a more positive selection means the opposite, as the country is left with a less-skilled workforce. In light of these predictions, we would expect a positive impact on GDP per capita in the US in 1880 and in Mexico in the 2000s, and a negative impact on Norway in 1865 and the US in the 2000s.

While the theory clearly predicts the sign of the aggregate effect, its size depends on the model parameters. The same holds for the share of workers in both sectors. While an increase in the skill levels shifts the cutoff skill-level between $Y$ and $X$ to the right, this may not necessarily mean that sector $Y$ will have a higher share of workers, as the sectoral distribution of workers depends on the size of the shift in the skill distribution.

The magnitude of the aggregate effects will depend on the share of migrants and the degree of selection. If the share of migrants is low compared to a country's population, the effects will be small regardless of the skill composition of the migrant flows. Given that in both cases people migrated from a smaller to a larger country, the relative population changes are naturally larger in the sending countries. As we can see in Table 1, the emigration of 183,000 Norwegians decreased the Norwegian population by $9 \%$, while it only increased the US population by $0.4 \%$. Likewise, the emigration of 10 million Mexicans to the US decreased the Mexican population by 9\%; the increase in the US population was smaller, but still amounted to $4.1 \%$. From these differences in population changes, we can expect the effects in Norway and Mexico to be larger than in the US.

Another determinant of the size of the effect will be the degree of migrant selection. The effects will be small if the degree of selection is small, which is the case if migrants have almost the same characteristics as all nationals from the country of origin. As Figure 4 shows, the degree of selection was a lot smaller in Norway in 1865 than in Mexico in the 2000s (Figure 5), which is why we would expect larger effects for the Mexican case, even if all other parameters were the same as in Norway in 1865. 
The gains and losses from selective migration, computed as the relative difference between baseline and counterfactual, are presented in Table 2 . For example, the change in the price index in Norway in Column (1) means that prices in Norway in 1865 were $0.11 \%$ lower because of self-selection.

Table 2: The gains and losses from migrant selection

\begin{tabular}{lcccccc}
\hline & \multicolumn{2}{c}{ Sending countries } & & \multicolumn{2}{c}{ Receiving countries } \\
\cline { 2 - 3 } \cline { 5 - 6 } & Norway 1880 & Mexico 2000s & & USA 1880 & USA 2000s \\
Changes in $\%$ & $(1)$ & $(2)$ & & $(3)$ & $(4)$ \\
Price index & -0.11 & -0.44 & & -0.00 & 0.18 \\
Real income p.c. & -0.24 & 0.89 & & 0.02 & -0.32 \\
\multicolumn{1}{l}{ Changes in percentage points } & & & & \\
Gini & 0.02 & -0.01 & & -0.00 & -0.03 \\
Employment $Y$ & -0.27 & -0.25 & & -0.00 & 0.07 \\
\hline
\end{tabular}

The aggregate effects for the sending countries is shown in the first two columns. For Norway, which had a slight positive selection of emigrants, this selection decreased GDP by $0.24 \%$, and it increased the GINI index by 0.02 points, while the employment share in sector $Y$ decreased by 0.27 percentage points. The effect on GDP in Norway is rather small, owing to the low degree of selectivity.

By contrast, the effects are considerably larger in Mexico. While migrant selection contributed little to wage inequality and the sectoral distribution, it had a significant impact on the prices and real income per capita. Because the 10 million Mexican emigrants were less skilled than the average Mexican, the country is left with a more productive workforce, and Mexican GDP is $0.89 \%$ higher.

The comparison between Mexico 2000s and Norway 1865 shows that migrant selection only matters if migrants are significantly different from the total population. Both countries had the same share of emigrants, yet Norwegian migrants had almost the same skills as those who stayed in Norway, whereas Mexican migrants had fundamentally different skills, leading to larger effects in Mexico.

In the US the aggregate effects are close to zero, as shown in Columns (3) and (4) of Table 2. The inflow of 183,000 Norwegians only caused an incremental increase of the US population, so that the composition of these flows had no impact. And although immigration from Mexico, 120 years later, happened at a much larger scale, the negative selection of Mexicans only had a small economically important effect on the US. The negative selection of Mexicans decreased US GDP by $0.32 \%$. This result may be surprising, given that Mexican immigration increased the US population by over $4 \%$ and given 
the significant negative selection. But the small effect in the US can be explained by the narrow skill dispersion of Mexican immigrants in the US. Despite Mexican migrants being drawn from all parts of the skill distribution in Mexico, they do not end up in the same decile of the US skill distribution after emigration. On the contrary, Mexicans are heavily concentrated at the lower end of the US skill distribution, as shown in Figure $9 \mathrm{~b}$. So even if the selection of migrants changes significantly with respect to the skill distribution in Mexico, it only marginally changes the skill distribution of Mexicans in the US.

Taken together, the results suggest that migrant self-selection can, but not necessarily has to, matter on the aggregate. While many studies on the causes of self-selection are motivated by the potential welfare consequences in the receiving countries, our results show that the effects in the US are close to zero. The effect is significant, however, in the sending countries, especially in Mexico. Mexican migrants are large in numbers and they differ considerably in their characteristics from the total population, which translates into a substantial effect on GDP per capita. In the next section we will check the robustness of these results to changes in the model assumptions, and assess the size of the effects.

\subsection{EXTENSIONS}

We now provide some further insights on the magnitude and sensitivity of these effects. We first ask whether the aggregate impact of selection in Mexico is indeed a large effect, by comparing the selection effect with a pure scale effect. Furthermore, we extend the model with international trade, and show how the simulation results change when migration alters both the skill distribution and the output mix of an economy. Finally, we derive an upper bound for the aggregate effect in the us, by asking what would be the impact on the US economy if all immigrants were selected like Norwegians or Mexicans.

Table 3: Extensions

\begin{tabular}{|c|c|c|c|c|c|c|}
\hline & \multicolumn{2}{|c|}{ Scale effect } & \multicolumn{2}{|c|}{ Trade response } & \multicolumn{2}{|c|}{ All migrants selected } \\
\hline & $\begin{array}{c}\text { USA 2000s } \\
\text { (1) }\end{array}$ & $\begin{array}{c}\text { Mexico 2000s } \\
\text { (2) }\end{array}$ & $\begin{array}{c}\text { USA 2000s } \\
(3)\end{array}$ & $\begin{array}{c}\text { Mexico 2000s } \\
\text { (4) }\end{array}$ & $\begin{array}{c}\text { USA } 1880 \\
(5)\end{array}$ & $\begin{array}{c}\text { USA } 2000 \mathrm{~s} \\
(6)\end{array}$ \\
\hline \multicolumn{7}{|l|}{ Changes in \% } \\
\hline Price index & 0.64 & -0.39 & 0.15 & 0.15 & -0.03 & 0.57 \\
\hline Real income p.c. & -1.11 & 0.80 & -0.38 & 1.23 & 0.15 & -1.08 \\
\hline \multicolumn{7}{|c|}{ Changes in percentage points } \\
\hline Gini & -0.01 & -0.15 & -0.07 & 0.00 & -0.02 & -0.09 \\
\hline Employment $Y$ & -0.23 & 0.31 & 0.44 & -2.73 & 0.00 & 0.16 \\
\hline
\end{tabular}

Note: Columns (1) and (2): scale effect of migration. (3) and (4): effect of selection with costless trade. (5) and (6): aggregate effect in the US if all migrants were selected like Norwegians/Mexicans. 


\subsubsection{Who Vs. HOW MANY? How important IS THE AgGREgATE EFFECT OF SELECTION?}

The simulations in the previous section show that migrant selection can have a significant impact on income per capita, provided the size of the migration flow and the degree of selection are sufficiently large. Among the four cases we consider, the positive effect of migrant selection on Mexican GDP stands out. Mexico is one of the largest migrant sending countries in the world, which is why we want to take a closer look at the aggregate effect there. Because Mexicans are to a large degree negatively selected, GDP per-capita is almost $1 \%$ higher than it would be if migrants were neutrally selected. But since we had no strong prior about the size of this effect, we would like to assess whether the increase is economically significant.

To assess the size of the selection effect, we compare it to an objective benchmark that has been widely studied in the literature - the impact of migration per se. While our selection effect purely measures the impact of who — changing the skill composition while leaving the number of migrants constant, most of the literature tries to estimate the impact of how much - leaving the skill composition constant while changing the scale of migration from zero to 10 million migrants. In the initial Edgeworth box in Figure 1, the scale effect is the difference between $A$ and $B^{\prime}$, while the selection effect is the difference between $B$ and $B^{\prime}$.

Columns (1) and (2) of Table 3 show the simulation results for the pure scale effect, which compares the Mexican economy under the currently observed migration scenario to a counterfactual economy without migration. The results show that the selection effect greatly matters in Mexico, while it is modest in the US. In Mexico, the selection effect of $+0.89 \%$ is even larger than the scale effect of $+0.80 \%$. Hence, to the same extent that it matters if 10 million Mexicans leave the country, it also matters that these 10 million have different skills compared to the total Mexican population. In the US, in contrast, the scale effect is almost four times larger than the selection effect. It matters almost four times more that 10 million Mexicans are in the US, than it matters that these are less-skilled than the average Mexicans. As shown in Figure 8, a change in the selection of 10 million Mexicans does not significantly change the skill distribution of Mexicans in the US. Yet, if the US were to entirely lose 10 million Mexicans, this would have a significant negative effect on US GDP of around $-1 \%$.

The comparison of the selection effect with the scale effect also solves an important conceptual issue of this study. In Section 4 we estimate the degree of selection of a migration flow, but then apply the estimate in the simulations to a migration stock. If, however, the selection pattern changes over time, our simulations may over- or under- 
estimate the aggregate effect. The aggregate impacts of a flow, i.e. a migration wave over 5 years, are most likely smaller than the effects based on stocks. But even if we were only interested in the marginal effect of the selection of the current flow, the difference between the selection and the scale effect tells us that the skill composition is as important as the size, as both effects can be scaled up or down due to the CRS technology in production. Hence, the ratio between both effects should remain the same even if the scale changes.

\subsubsection{ACCOUNTING FOR TRADE RESPONSES}

The benchmark simulations in Section 5.2 were carried out for each country in autarky. Yet, a change in the skill composition of migrants changes the relative skill endowment of each economy. Negative selection of Mexicans, for example, means that Mexico becomes relatively more skilled and the US relatively less. In autarky, the economy adjusts to changes in the skill composition of the workforce with a shift in the sectoral distribution of skills. The resulting surplus effect is positive in Mexico, because Mexico is left with a more productive workforce, and is negative in the US.

If both countries trade with each other, changes in the skill endowment has an additional effect on the sectoral distribution of skill types, as it may induce a different specialization pattern. Suppose Mexico is initially specialized in agricultural production - having a relatively larger $Y$-sector than the US. Negative selection of emigrants then has two effects: a positive effect because Mexican workers become more productive on average, and a change in the trade patterns, which can be positive or negative.

To assess the robustness of our results when we allow for trade, we compare the aggregate effect under autarky to the effect in an economy with costless trade. While these are polar cases, they provide bounds to the actual effect. In online Appendix E we explain how we incorporate trade into the baseline model. For calibration we use the same population numbers, immigrant numbers, fixed costs, and returns to skill as in the autarky case. For better tractablility we now assume that the preference parameters are the same across countries, and choose similar values to the ones obtained in Section 5.1 , $\beta=0.5, \theta=1.4$, and $\sigma=3.7$.

As Columns (3) and (4) in Table 3 show, under autarky we actually under-estimate the impact of self-selection. Under costless trade the effects on real income per capita are smaller compared to the benchmark, but the difference is minor. The effect in Mexico is $+1.23 \%$ instead of around $+1 \%$, while the effect in the US is now $-0.38 \%$ as opposed to $-0.32 \%$ in the benchmark. The results with trade confirm, however, that the selection of migrants changes the specialization pattern of both economies. In Mexico the employment in sector $Y$ decreases by 2.73 percentage points, while it increases by 0.44 percentage 
points in the US.

In sum, the results do not crucially hinge on the autarky assumption. The responses are of similar magnitude under autarky and under completely free costless trade.

\subsubsection{WHAT IF ALL IMMIGRANTS WERE SELECTED LIKE NoRWEGIANS / MeXICANS?}

So far, our results demonstrate that the selection of Norwegians in 1865 and Mexicans in the 2000s has almost zero impact on the US economy. But both groups are only one among many immigrant groups in the US. The selection of one group may not matter for the US as a whole, but it would matter if all immigrants in the US were selected according to a given pattern. To quantify this effect, we conduct the following thought experiment in the US in 1880 and in the 2000s: suppose all immigrants in the US were selected like Norwegians or Mexicans, what would be the aggregate effect on US GDP per capita.

Even if we impose the same selection pattern on all US immigrants, the effects remain small. As shown in Columns (5) and (6) of Table 3, the impact on real income per capita is larger by a factor 7 in 1880 and a factor 3 in 2000, but still only amounts to a $0.15 \%$ increase in 1880 and a $1.08 \%$ decrease in 2000 .

These findings suggest that self-selection most likely only matters for the sending countries. In the US, given the concentration of immigrants in the lower end of the skill distribution, and the narrow skill dispersion of immigrants, even a significant change in the selection pattern does not lead to large effects on the aggregate.

\section{Conclusion}

Migrant self-selection is a central theme in the study of migration. A large literature investigates causes of migrant selection; it documents that migrants significantly differ from non-migrants with respect to many characteristics, and investigates which factors determine who migrates and who stays. In this paper we ask whether migrant selection actually has any impact on the sending and receiving countries. To quantify the effect of selection on per-capita income and income inequality, we use two mass migration episodes that occurred in different times, but at a similar scale: the migration of Norwegians to the US in 1880, and the migration of Mexicans to the US in 2000. In both cases, emigration decreased the population of the sending countries by $9 \%$, but selection was positive in Norway and negative in Mexico.

We first estimate the degree of self-selection for both countries, confirming previous 
findings from the literature that Norwegians were on average positively, and Mexicans negatively selected from the respective populations (Fernández-Huertas Moraga, 2011, Abramitzky et al. 2012). To quantify the aggregate effect, we conduct a thought experiment: we send all immigrants back to their sending country, and replace them by the same number drawn at random from the total population. Put differently, we compare aggregate outcomes under the observed selective migration flows with a counterfactual scenario, in which migrants have the same characteristics as all nationals of the sending country. For the simulations we use a general equilibrium model with heterogeneous workers, based on the work by Yeaple (2005) and Iranzo \& Peri (2009), calibrated on the economies of Norway, Mexico, and the US in the 1880s and 2000s.

Our findings demonstrate that migrant self-selection matters on the aggregate, but only if a number of conditions are met. Negative selection induces emigration of the least-skilled workers of a sending country, leaves the country with a more productive workforce, and thus increases output per capita, while it has the opposite effect in the receiving countries. However, these effects are only significant if the share of migrants and the degree of selection are sufficiently large. If the size of the migration flow relative to the total population is small, then the skills of migrants don't matter on the aggregate. If migrants are similar to non-migrants, emigration leaves the skill composition of the sending country unchanged, and does not affect income per capita. Norwegian migrants in the 1880s had very similar skills compared to non-migrants, which leaves income per capita and prices in both Norway and the US unaffected. For the Mexican migration episode, however, our model predicts sizable aggregate effects. The negative self-selection of 10 million Mexicans increases real income per capita by $0.89 \%$. This effect as large as aggregate impact of migration per se - the difference between no migration and the current level of migration, which in our simulations is $+0.80 \%$. Besides the effect on income levels, migrant selection has no impact on the income distribution.

The literature often motivates studying self-selection with potentially large welfare effects in the receiving countries. Our results suggest that the impact on the receiving countries is - at best - modest. The immigration of 10 million negatively selected Mexicans decreased real per-capita incomes in the US by $0.32 \%$. Two stylized facts can explain why this effect is not larger. First, the US population is larger than the population in Mexico, so that the relative size of the migration flow is smaller. Second, the skill dispersion of migrants in the sending country is wider than in the host country. In the US, immigrants are concentrated at the lower end of the skill distribution, while the same migrants come from the entire range of skills in Mexico and Norway. Under these conditions, even a significant change in the selection pattern in the sending country has a modest effect on the skill distribution of immigrants in the US, and translates into 
small aggregate effects. Even if we assume that all immigrants in the US are selected like Norwegians or Mexicans, the impact on per-capita income is $+0.15 \%$ and $-1.08 \%$, respectively.

In light of these findings, researchers need to be careful claiming that selection has significant welfare impacts. More often than not, the conditions for observing a large welfare impact are not met. Among the four cases presented in this paper - Mexico, Norway, and the US in 1880 and the 2000s - selection has an impact close to zero in three of them. Studying self-selection of migrants may be a worthwhile demographic exercise, and may enhance our understanding of migration processes in general, but we have to be careful - not to say selective - when it comes to claiming that it has broader economic consequences.

The online Appendix can be accessed at the following link: https://www.dropbox. $\mathrm{com} / \mathrm{s} /$ beoamb7jzc5p31t/appendix.pdf. 


\section{REFERENCES}

Abramitzky, Ran, Boustan, Leah Platt, \& Eriksson, Katherine. 2012. Europe's Tired, Poor, Huddled Masses: Self-Selection and Economic Outcomes in the Age of Mass Migration. American Economic Review, 102(5), 1832-1856.

Akee, Randall K. Q. 2007. Who Leaves and Who Returns? Deciphering Immigrant Self-Selection from a Developing Country. IZA Discussion Paper, 3268.

Ambrosini, J. William, \& Peri, Giovanni. 2012. The Determinants and the Selection of Mexico-US Migrants. The World Economy, 35(2), 111-151.

Ambrosini, J. William, Mayr, Karin, Peri, Giovanni, \& Radu, Dragos. 2011. The Selection of Migrants and Returnees: Evidence from Romania and Implications. NBER Working Paper, 16912.

Bartolucci, Cristian, Villosio, Claudia, \& Wagner, Mathis. 2013. Who Migrates and Why? Collegio Carlo Alberto, mimeo.

Belot, Michèle V. K., \& Hatton, Timothy J. 2012. Immigrant Selection in the OECD. The Scandinavian Journal of Economics, 114(4), 1105-1128.

Bertoli, Simone. 2010. The Informational Structure of Migration Decision and Migrants Selection. Economics Letters, 108, 89-92.

Bertoli, Simone, \& Rapoport, Hillel. 2013. Heaven's Swing Door: Endogenous Skills, Migration Networks and the Effectiveness of Quality-Selective Immigration Policies. IZA Discussion Paper, 7749.

Bertoli, Simone, Fernandez-Huertas Moraga, Jesus, \& Ortega, Francesc. 2010. Crossing the Border: Self-Selection, Earnings and Individual Migration Decisions. IZA Discussion Paper, 4957.

Biavaschi, Costanza. 2012. Recovering the Counterfactual Wage Distribution with Selective Return Migration. IZA Discussion Paper, 6795.

BorJas, George J. 1987. Self-Selection and the Earnings of Immigrants. The American Economic Review, 77(4), 531-553.

Borjas, George J., \& Bratsberg, Bernt. 1996. Who Leaves? The Outmigration of the Foreign-Born. The Review of Economics and Statistics, 78(1), 165-176. 
Borjas, George J., Bronars, Stephen G., \& Trejo, Stephen J. 1992. SelfSelection and Internal Migration in the United States. Journal of Urban Economics, 32(2), 159-185.

Borjas, George J., Grogger, Jeffrey, \& Hanson, Gordon H. 2008. Imperfect Substitution between Immigrants and Natives: a Reappraisal. NBER Working Paper, 13887.

Borjas, George J., Kauppinen, Ilpo, \& Poutvaara, Panu. 2013. Self-Selection of Emigrants from a Welfare State. University of Munich, mimeo.

Brücker, Herbert, \& Trübswetter, Parvati. 2007. Do the Best Go West? An Analysis of the Self-Selection of Employed East-West Migrants in Germany. Empirica, 34, 371-395.

Carrington, William J., Detragiache, Enrica, \& Vishwanath, Tara. 1996. Migration with Endogenous Moving Costs. The American Economic Review, 86(4), 909-930.

Caselli, Francesco, \& Coleman, Wilbur John. 2006. The World Technology Frontier. The American Economic Review, 96(3), 499-522.

Chiquiar, Daniel, \& Hanson, Gordon H. 2005. International Migration, SelfSelection and the Distribution of Wages: Evidence from Mexico and the United States. Journal of Political Economy, 113(2).

Chiswick, BARry R. 1999. Are Immigrants Favorably Self-Selected. The American Economic Review Papers and Proceedings, 89(2), 181-185.

de Coulon, Augustin, \& Piracha, Matloob. 2005. Self-Selection and the Performance of Return Migrants: the Source Country Perspective. Journal of Population Economics, 18, 779-807.

Di Giovanni, Julian, Levchenko, Andrei A., \& Ortega, Francesc. 2012. A Global View of Cross-Border Migration. IZA Discussion Paper, 6584.

Duajić, Slobodan, Michael, Michael S., \& Vinogradova, Alexandra. 2012. Migration of Skilled Workers: Policy Interaction between Host and Source Countries. Journal of Public Economics, 96(11-12), 1015-1024.

Docquier, Frédéric, Machado, J oel, \& Sekkat, Khalid. 2012. Efficiency Gains from Liberalizing Labor Mobility. IRES Discussion Paper, 23. 
Facchini, Giovanni, \& Testa, Cecilia. 2011. The Rhetoric of Closed Borders: Quotas, Lax Enforcement and Illegal Immigration. CEPR Discussion Paper, 8245.

Felbermayr, Gabriel J., \& Kohler, Wilhelm. 2007. Immigration and Native Welfare. International Economic Review, 48(3), 731-760.

Fernández-Huertas Moraga, Jesús. 2011. New Evidence on Emigrant Selection. The Review of Economics and Statistics, 93(1), 72-96.

Fernández-Huertas Moraga, Jesús. 2013. Understanding Different Migrant Selection Patterns in Rural and Urban Mexico. Journal of Development Economics, forthcoming.

Fernández-Huertas Moraga, Jesús, \& Rapoport, Hillel. 2013. Tradable Immigration Quotas. CESifo Working Paper, 4087.

Ferrie, Joseph P. 1996. A new sample of males linked from the public use microdata sample of the 1850 US federal census of population to the 1860 US federal census manuscript schedules. Historical Methods: A Journal of Quantitative and Interdisciplinary History, 29(4), 141-156.

Goldin, Claudia, \& Katz, Lawrence F. 2007. Long-Run Changes in the Wage Structure: Narrowing, Widening, Polarizing. Brookings Papers on Economic Activity, 38(2), 135-165.

Hamilton, Bob, \& Whalley, John. 1984. Efficiency and Distributional Implications of Global Restrictions on Labour Mobility: Calculations and Policy Implications. Journal of Development Economics, 14(1-2), 61-75.

Ibarraran, Pablo, \& Lubotsky, Darren. 2007. Mexican Immigration and SelfSelection: New Evidence from the 2000 Mexican Census. Chap. 5, pages 159 - 192 of: Borjas, George J. (ed), Mexican Immigration to the United States. University Of Chicago Press.

Iranzo, Susana, \& Peri, Giovanni. 2009. Migration and Trade: Theory with an Application to the Eastern-Western European Integration. Journal of International Economics, 79, 1-19.

Jensen, Adolph. 1931. Migration Statistics of Denmark, Norway and Sweden. Pages 283-312 of: International Migrations, Volume II: Interpretations. NBER. 
Kaestner, Robert, \& Malamud, Ofer. 2013. Self-Selection and International Migration: Evidence from Mexico. Review of Economics $\&$ Statistics, forthcoming.

Kanbur, Ravi, \& Rapoport, Hillel. 2005. Migration Selectivity and the Evolution of Spatial Inequality. Journal of Economic Geography, 5, 43-57.

Kennan, John. 2013. Open Borders. Review of Economic Dynamics, 16(2), L1-L13.

Klein, Paul, \& Ventura, Gustavo. 2007. TFP Differences and the Aggregate Effects of Labor Mobility in the Long Run. B.E. Journals in Macroeconomics, 7(1).

Klein, Paul, \& Ventura, Gustavo. 2009. Productivity Differences and the Dynamics of International Labour Movements. Journal of Monetary Economics, 56, 1059-1073.

Lacuesta, Aitor. 2010. A Revision of the Self-selection of Migrants Using Returning Migrant's Earnings. Annales d'Economie et de Statistique, 97/98, 235-259.

McKenzie, David, \& Rapoport, Hillel. 2010. Self-Selection Patterns in MexicoU.S. Migration: The Role of Migration Networks. Review of Economics and Statistics, 92(4), 811-821.

McKenzie, David, Stillman, Steven, \& Gibson, John. 2010. How Important is Selection? Experimental vs. Non-Experimental Measures of the Income Gains from Migration. Journal of the European Economic Association, 8(4), 913-945.

Minnesota Population Center. 2008 (Minneapolis: Minnesota Population Center,). North Atlantic Population Project: Complete Count Microdata. Version 2.0 [Machinereadable database].

Orrenius, Pia M., \& Zavodny, Madeline. 2005. Self-Selection among Undocumented Immigrants from Mexico. Journal of Development Economics, 78, 215-240.

Ottaviano, Gianmarco, \& Peri, Giovanni. 2012. Rethinking the Effects of Immigration on Wages. Journal of the European Economic Association, 10(1), 152-197.

Pedersen, Peder J., Pytlikova, Mariola, \& Smith, Nina. 2008. Selection or Network Effects? Migration Flows into 27 OECD Countries, 1990-2000. European Economic Review, 52, 1160-1186.

Piracha, Matloob, \& Vadean, Florin. 2013. Migrant educational mismatch and the labour market. In: Constant, Amelie F., \& Zimmermann, Klaus F. (eds), International Handbook of the Economics of Migration. Edward Elgar. 
Rooth, Dan-Olof, \& SaArela, Jan. 2007. Selection in Migration and Return Migration: Evidence from Micro Data. Economics Letters, 94(1), 90-95.

van Leeuwen, Marco, MaAs, Ineke, \& Miles, Andrew. 2002. HISCO - Historical International Standard Classification of Occupations. Leuven University Press.

Williamson, Jeffrey G. 1995. The Evolution of Global Labor Markets since 1830: Background Evidence and Hypotheses. Explorations in Economic History, 32, 141-196.

Xing, Chunbing. 2010. Migration, Self-Selection and Income Distributions: Evidence from Rural and Urban China. IZA Discussion Paper, 4979.

Yeaple, Stephen Ross. 2005. A Simple Model of Firm Heterogeneity, International Trade, and Wages. Journal of International Economics, 65, 1-20. 